altitude and of van Allen particles at higher altitude. In his article (Science and Culture, 27, No. 11; November 1961) Prof. Saha directs particular attention to the effect of anoxia and the effects of sudden exposure to low atmosphere oxygen content.

\section{Bait Selection by Rats}

THE problem of using an attractive bait during mass-destruction campaigns of rats is of great economic importance. Often these campaigns have to be carried out under conditions where rats have access to abundance of choice foods and even water. Any information which can be obtained on bait selection by rats in these circumstances is useful in the protection of stored foodstuffs against rats. To show whether rats would select any one bait offered under the same conditions, a series of trials were carried out in granaries on the Far East Rand (South African Journal of Science, 2, No. 57; November 1961). Fish meal, maize meal and water baits were used during the investigations by Karl HechterSchulz, who also examined the feeding pattern of the rats and the effect which types of building have on this. A state of rat control resulted from the operation rather than the desired census on which reliable observations could be based. The results show that the method of offering the bait, as well as the provision of conditions of security while feeding, play a prominent part in bait selection by rats.

\section{Pulmonary Tuberculosis among Older Europeans in Central Africa}

Dr. Charles Shee, consulting physician, Bulawayo Hospital, has investigated the cases of pulmonary tuberculosis admitted to the City Infectious Diseases Hospital, Bulawayo (Central African Journal of Medicine, 7, No. 9; Sept. 1961). The average age of fifty-five European patients discovered to have pulmonary tuberculosis in Matabeleland between 1953 and 1958 was forty-two years. The average age of twenty patients diagnosed in 1959 and the first four months of 1960 was fifty-nine years. This difference is statistically significant and unlikely to have arisen by random sampling. A variety of factors may be concerned, such as an ageing population, a loss of acquired rosistance with increasing age, readier access to radiology, more awareness of the possibility of the infection in old age, and rising cost of living with lowered living conditions. But while these factors may to some extent explain the greater frequency with which pulmonary tuberculosis is diagnosed in old age, they fail to account for the sudden decrease in younger people. The cases exemplified show that the infection may be most insidious and only revealed when some coincidental or apparently unrelated condition leads to the patient being fully investigated. No explanation is offered for this sudden increase in age, but some of the implications are considered. Dr. Shee is anxious to know if a similar sudden change in the natural history of the disease has occurred among Europeans and Africans in other parts of Central and Southern Africa.

\section{Hormonal Control of Growth}

IN his Brailsford Robertson Memorial Lecture, which was delivered to the Medical Sciences Club of South Australia, Adelaide, on October 26, 1960, Prof. F. G. Young (University of Cambridge) described some of the research work which led him to enter a number of cognate fields of investigation. During the lecture he described in detail how, in 1936, he set out to isolate from the anterior pituitary tissue of oxen the substance which had been shown to be capable of inducing diabetes on daily administration to a partially depancreatinized dog, and how oventually he was tempted into much investigation on the endocrine control of growth and the part played therein by insulin. The lecture has now been published as a special supplement to the Australian Journal of Experimental Biology and Medical Science (39, Special Supplement, August 1961. Pp. 14. Adelaide: University of South Australia, 1961).

\section{Atypical Mycobacteria}

IN the sixteenth annual report of the Queensland Institute of Medical Research for the year ended June 30, 1961, an account is given of studies of some atypical Mycobacteria (Pp. 13. Brisbane: Queensland Institute of Medical Research, 1961). The investigation began three years ago as an attack on the problem presented by a high incidence of positive Mantoux reactions in children in North Queensland. It has been developed in three inter. locked phases: a general survey of the incidence of atypical Mycobacteria in relation to the frequency of positive reactions in children; a study of their classification; and an experimental study of their sensitizing ability. Some subsidiary inquiries have also been undertaken. The report also describes work carried out in the fields of mycology, venal infections, parasitology, and entomology. Descriptions are given of the work of the Innerfail Field Station and methods adopted to provide clean animals for parasitological work.

\section{Food and Agriculture Organization André Mayer Fellowships}

The Food and Agriculture Organization of the United Nations is offering ten or twelve André Mayer Fellowships for individual research work or for research training for younger scientists, particularly those from countries where research facilities are not highly developed. Research presented should pertain to one of the following subjects: land and water development; plant production and protection; animal production and health; rural institutions and services; fisheries; forestry and forest products; non-medical nutrition; atomic energy in food and agriculture; agricultural economics. Application forms and further information can be obtained from the Secretariat of the Food and Agriculture Organization National Committee for the United Kingdom, Ministry of Agriculture, Fisheries and Food, Whitehall Place (East Block), London, S.W.1.

\section{The Microchemistry Group}

Ar the eighteenth annual general meeting of the Microchemistry Group of the Society for Analytical Chemistry held on February 23, at the Chemical Society, Burlington House, Piccadilly, London, the following were elected officers of the Group for the forthcoming year: Chairman, Mr. C. Whalley; Vice-Chairman, Miss M. Corner; Honorary Secretary, Mr. D. W. Wilson, Sir John Cass College, Jewry Street, Aldgate, London, E.C.3 ; Honorary Treasurer, Mr. G. Ingram.

\section{International Starch Conference}

THE international starch conference, organized by the West German Starch Research Station, Detmold, 